\title{
Socio-Cultural Factors Affecting Reintegration of Discharged Prisoners in Anambra State, South East, Nigeria
}

\author{
Osayi Kelechi K.
}

\section{Doi:10.5901/mjss.2013.v4n10p775}

\section{Abstract}

\begin{abstract}
In recent time, recidivism has not only been on the increase in sub- Saharan Africa, but has become a major social problem to the society, governments, multinational humanitarian organizations and the world over. Discharged prisoners find it difficult to reintegrate into the society because of some social and cultural factors which seem to inhibit all efforts geared towards their rehabilitation and reintegration. It is against this background that this paper aimed at examining the socio-cultural factors affecting the rehabilitation and reintegration of discharged prisoners in Anambra state. This study was anchored on two theoretical premises; the rehabilitation and ecological theories. The rehabilitation theory was adopted to drive home the correctional philosophy of the modern prison system which emphasizes treatment of offenders rather than punishment. Ecological theory brings out the significant influence environmental factors have on individual's behavior. Implicit in the Ecological theory is the idea that reintegration of discharged prisoners may become nearly impossible if the environment is not conducive for discharged prisoners. It is important to reconstruct environment that supports individual's post incarceration needs, so that the society can prevent multiple offenses and reduce recidivism rates and crime.
\end{abstract}

Keywords: Recidivism, rehabilitation, reintegration, discharged prisoners, socio-cultural issues, Anambra, Nigeria, Africa.

\section{Introduction}

In recent time, recidivism has not only been on the increase in sub- Saharan Africa, but has become a major social problem to the society, governments, multinational humanitarian organizations and the world over. Discharged prisoners find it difficult to reintegrate into the society because of some social and cultural factors which seem to inhibit all efforts geared towards this direction. Recidivism is surely on the increase in Nigeria and Anambra state having one of the most densely populated cities in Nigeria accounts for a reasonable percentage of this group. As a typical southeastern state of the Igbo extraction, it has maintained a strong cultural belief system which has influenced her world view including the way her members relate and perceives discharged prisoners.

Before the society as a corporate body, took over the function of working to control the antisocial behaviour of her members, Imogen (2007) observed that individuals and families seek redress/revenge to offences committed against them by using what is known to be the oldest codified law of "a tooth for a tooth" and "an eye for an eye". Societies develop, treatment of offenders at every stage depended on the societal perception of them. Carney (1977) and Imogen (2007) noted that in the ancient Rome for instance, offenders were perceived as traitors, sinners, bandits, criminals and therefore were severely punished with such punishment as throwing into the lion's den, or burning furnace, and even frying alive in a pot of oil. They used public flogging, crucifixion, impaling, beheading, hanging, mutilation, stoning, exiling, and shooting with arrow or spear, as punishment depending on the degree of offences committed or the mood of the king or the emperor both in England, France and in fact, all over Europe and more were ingeniously invented to suit new offences and to serve the whims and caprices of the rulers (Carney, 1997 \& Shama, 2012).

In the traditional pre-colonial African societies, offenders were seen as enemies of the gods of the land whose offences attracted the wrath of the gods on the whole society (Igbo, 1999). Therefore, evildoers or violators of the laws of the land were perceived and treated as outcasts, evil and wicked their punishment ranged from public humiliation, flogging, temporal excommunication, payment of fine, to performance of sacrifices to appease the gods and to cleanse themselves of the offences committed before they could be reintegrated into the society. This was also typical of the traditional Igbo societies within the southeastern Nigeria (Igbo, 1999). Traditional African societies, especially those in the southeastern Nigeria seem to have over time, developed a strong belief system influencing their relationship with members who at one time or the other violated the laws of the land, which was seen as effrontery to the gods who were their custodians. This belief system seem to have however been carried over to the present day society, even with the introduction of modern prison philosophy were offenders are no longer considered as outcasts but as human beings who could be reformed and rehabilitated with the hope of being reintegrated into the society one day. Despite this positive 
development, the negative perception and treatment of discharged prisoners especially those who have passed through the prison institution in Anambra state still persist.

Falobi (2009) stressed that over the years, there has been a radical shift in penal philosophy and management globally, from imprisonment for punishment to imprisonment for reformation, rehabilitation and reintegration. This new orientation emphasizes the identification of the reason for individual's anti social behaviour for treatment. The offender is then returned to the society not as a social misfit but reoriented and well equipped for productive life. To the contrary however, Ugwuoke (2010) observed that one of the fundamental issues facing prison administration in Nigeria today is lack of agreement as to what should be the aim of dealing with convicted offenders. According to him, in principle, Nigeria prison preaches reformation and rehabilitation, but in practice, it advocates for retributive punishment. He maintained that their punishment continues even after discharge from the prison due to public attitude towards them, as they are branded and treated as ex-convicts (stigma) which however is the greatest obstacle to a discharged prisoner's re-integration. This stigma is emphasized by the legal or state law which so defines the discharged prisoner. They are prohibited from employment to certain positions and occupation of public offices. Therefore, the law as it exists today further stigmatizes the discharged prisoner and prevents him from integrating successfully.

In Nigeria, between 1990 and 2000, the awaiting trial persons constituted 70\% of prison population. From the year 2000-2010, their population was fluctuating around $62 \%$ of a total prison population of about 44,000 . Between 2010 and 2011 , out of a total prison population of 40,447, a total 25,380 (63\%) persons are awaiting trial. It was however noted that more than half of awaiting trial persons as captured by annual reports have been convicted more than once (Orakwe, 2011). Currently, (January -July, 2013) prison population stands at 53,815 inmates, out of which 37,429 inmates are awaiting trial while 16,387 inmates are convicted (Prison Quarterly Statistics, Abuja). Inferring from the above statistics, recidivism is high in Nigeria prison. It has been noted that Nigerian prison has proved dysfunctional, for rather than reconciling the offender with the social order and its laws, the prison has been a center for the dissemination and exchange of criminal influences and ideas, and has usually rendered the prison processed offenders unable to reintegrate into the society, (Ugwuoke, 2010).

Lack of funding appears to be the main reason for lack of materials and failure to replace worn-out equipments and machines used for reformation and rehabilitation (Uma, 2004). Lack of qualified personnel to operate these machines and engage the prisoners in meaningful course of training has also been identified as a major factor. At the end, the prisoner may be discharged without being reformed or rehabilitated. The government scheme of funding a prisoner upon discharge seems no longer a priority and this goes a long way in explaining the high rate of recidivism in the Nigerian prisons. This is because they still cannot find their footing in the society even after discharge. Therefore, society still perceives them as social misfits who should be avoided thereby making reintegration impossible.

The highly restricted nature of the prison yard to members of the public as expressed by Adigwe is also another factor, when he stated that the prison yard is a no-go-area, just as passing through its gate is highly restricted and nearly impossible for visitors. This most likely creates an unhealthy gap between the prisoner and his/her family and friends thereby widening the gap between the prisoner and the very people he/she is going home to after discharge (Adigwe as cited in Uma, 2004).

Ekpe \& Mammah (1997) and Ugwuoke (2010) noted that government seems to have little or no provision for gainful employment opportunities or arrangement for proper rehabilitation of discharged prisoners in our society. The social stigma "ex-convict" attached to them seems to have contributed to their problem of resettlement in the society. It looks as if one automatically becomes an outcast and ostracized once one is discovered to have been in and out of prison. Many family members in the Igbo speaking states such as Enugu, Anambra and Imo disown their members and deny them some family rights just because they have been to prison and are therefore criminals (Ekpe \& Mammah, 1997). This demonstration of rejection and neglect by both the families and the communities which are supposed to join hands and provide for the discharged prisoners until they are able to adjust to life in the free society, practically do not seem to save the situation.

It is noteworthy that the intended objective of rehabilitation of prisoners may not be achieved if their reintegration into the society fails. Unfortunately, the complementary follow-up after-care services of the prison for discharged prisoners which ensure smooth reentry into the society appears to be totally lacking, probably as a result of shortage of personnel or lack of professionals.

Lack of sincere effort in pursuing the legislative provisions (if any) for discharged prisoners in the area of community rehabilitation and reintegration programme, the legal stipulation that denies them employment and public appointments as well as the age long traditional apathy towards discharged prisoners are all encapsulated in the societal perception of them deeply rooted in cultural disposition. This study, therefore, seeks to examine the socio-cultural factors 
affecting the re-integration needs of discharged prisoners in Anambra state.

\section{Rehabilitation and Reintegration challenges of Discharged Prisoners}

Studies have shown far ranging implications of social and cultural factors to the reintegration of discharged prisoners in the society. Immerwahr and Johnson (2002) in their study of perception of discharged prisoners noted that prisoner's reintegration into the community was a rarely discussed issue. Nobody seemed to care about what happened to prisoners that were released into the community - how they were treated and whether they would be able to rebuild their lives. The respondents believed that while prisoners had very little chance to learn useful skills in prison, they had ample opportunity to acquire and reinforce negative behaviors. The study painted a predictable and distressing picture of prisoners leaving prison with few new positive or marketable skills and many bad habits. They have no supervision and have a hard time finding a job including their inability to vote, and drive, etc contribute to their frustration and drive them back to crime. All of these, most of the respondents believed, lead to high rates of recidivism and a 'virtual revolving door', with people going back into prison almost as fast as they leave it.

Findings have also indicated that ex-offenders respond usually respond to the obvious socio-cultural implications of their new status which invariably attracts limited social and economic prospects, by placing themselves in tight-knit insular networks of family and close friends for both material and non-material benefits essential to daily life. Successful re-entry requires ex-offenders to seek help from individuals and organizations that have the capacity to provide assistance and/or employment opportunities. Such resources are usually external to the ex-offenders immediate insular network (ICJIA, 2007). It has been noted that, ex-offenders have expressed the desire to live more honestly," and to completely overhaul themselves, their lives, their kinship ties, and their views on the world if there are enabling laws and environmental conditions which obviously have eluded them.

Igbo and Ugwuoke in 2003 published the findings of a study they conducted with a sample of 200 prisoners in Enugu prison, southeast Nigeria, with the intention of finding out the factors contributing to high recidivism in Enugu prison. The findings revealed that there is actually a high recidivism rate in Enugu prison which the researchers attributed to poor environmental conditions of the prison and the negative attitude of the public towards ex-convicts as the two major factors.

Many prisoners actually come out of the prison truly repentant even without adequate reformation and rehabilitation. This is because deprivation of freedom and the harsh condition of the prison, that prisoners experience for as long as their sentences last actually instill the spirit of repentance and change of behaviour in them. It is the uncooperative and antagonistic attitude of the society together with the social stigma attached to "ex-convicts" that make their reintegration nearly impossible and therefore crime becomes their only source of solace and livelihood, (Ugwuoke, 2010).

Furthermore, the social, medical, emotional, and legal challenges ex-prisoners face stifle their willingness and ability to prepare adequately for reintegration and to refrain from recidivistic behaviors. Confronted with uncertainty, animosity, and a multitude of personal, social, and legal barriers, most prisoners reenter what they perceive to be an antagonistic society with a defeatist attitude, and if not addressed, this attitude will likely lead to reintegration failure (Osaze, 1996).

The importance of prisoner's reintegration seems to have been ignored by policy makers and correctional administrators. High recidivism rate indicates that inmates are not prepared to come back to society as law-abiding citizens. This is because major issues about their resettlement is poorly coordinated and has failed to address social exclusion issues such as housing and addiction problems that could lead people back into crime (Berty, 2001). They are normally set free without proper arrangement for their rehabilitation and reintegration in the society. Instead the law itself denies them some civic rights as free citizens. They are not allowed to hold public offices as they are seen as being untrustworthy and unreliable. These, according to Osaze, are strong factors that militate against prisoners' reintegration within the community. Although there are a number of non-governmental agencies who are trying to champion the course of released offenders, their efforts are quite insignificant. This has been found to be one of the reasons for the high incidence of recidivism in Nigeria.

In the opinion of Falobi (2009), after-care services will facilitate a responsive and understanding public attitude towards prison, its inmates, as well as the discharged prisoners. In Nigeria the reverse seem to be the case. Ekpe \& Mammah, (1997), maintain that the discharged prisoner and all connected with him/her bear an odious stigma. It matters little that the discharged prisoner may have ended up in the prison for purposes that may not be connected with crime. Communities where discharged prisoners come from are guilty for rejecting them to the point that they do not give them a 
chance to participate in most of the rituals and ceremonial activities that go on in those communities because of the belief that they are defiled (Ekpe \& Mammah, 1997).

\section{Theoretical Orientation}

Scholars have tried to provide an understanding of the relationship between some social and cultural factors and the reintegration challenges of discharged prisoners. One of such theoretical orientations is Rehabilitation theory. Hampton as cited in Brooks (2009) tries to justify essence of Rehabilitation theory by emphasizing treatment of discharged offenders for smoother and more profitable reintegration for their benefit and that of the society at large. This theory as noted by Brooks (2009) has the prevailing modern view that punishment should be reformative. The ultimate objective of punishment, in this view, is to bring about social tranquility. This theory argues that people are self-determinate beings whose ability to freely choose is frequently obstructed by various social conditions such as unequal access to social resources, poverty, unemployment, corrupt political system etc, which might lead to alcoholism, drug addiction, psychosis and crime etc. Therefore, the theory emphasizes treatment programmes that have the goals of making offenders lawabiding self-dependent member of the society. Treatment in this context can be defined as any and all efforts aimed at the remission of criminal behaviour and the social reintegration of the offender within the community. Thus, rehabilitation theory is all about the treatment and subsequent reintegration of the offender. It is motivated by humanitarian's belief in the worth and dignity of human person and the willingness to expand the effort to re-claim the criminal for his own sake and not merely to protect the society, (Match \& Jose, 1991). The humanitarians fostered the belief that punishment should be therapeutic rather than punitive in the interest of the offender and the society.

Another theoretical perspective is the Ecological Theory which supports the idea that changes in social environment have a notable influence on individuals. It is important to construct environments that support individuals post incarceration, so that we as a society can prevent multiple offenses and reduce recidivism rates and crime (Santrock, 2004). By inference, assumption can be made that availability of resources, treatment, and support services, societal attitudinal change etc, post-incarceration may indeed have a significant impact in declining the current rates of recidivism. Providing discharged prisoners with resources such as regular, stable employment will keep them out of 'informal economies' and 'secondary labor markets', where they are more vulnerable to re-offend. It would also be very beneficial to supply inmates with resources and education, provided by family educators that empower them to create healthier family and community environment. Ecological Theory supports the idea that resource availability would create a positive environmental support structure for post-incarcerated individuals and would be very effective in reducing recidivism rates.

To date, very few literature have actually addressed the issue of socio-cultural factors as they contribute to the rehabilitation and reintegration needs of discharged prisoners. This study is therefore an attempt to do this. In this study, attempt is made to fulfill the fallowing core objectives;

1. To ascertain how perception affects the rehabilitation and reintegration of discharged prisoners within their communities in Anambra State

2. To ascertain the effect of existing laws in the rehabilitation and reintegration of discharged prisoners within their communities in Anambra State

3. To examine to what extent cultural beliefs and practices have affected the rehabilitation and reintegration of discharged prisoners in Anambra State

4. To examine to what extent lack of adequate reformation and rehabilitation of prisoners within the prisons affect their reintegration in the society in Anambra State

\section{Significance of the study}

Apart from reducing crime rate and recidivism, the study will advocate for Practical and conscientious positive actions towards enhancing the conditions of the discharged prisoners in the Nigeria society especially in Anambra State. In practical terms, the findings of this study will bring to the fore the inadequacies, deficiencies, flaws and other problems inherent in the process of reformation and rehabilitation of prisoners in the Nigerian Prisons. This study will attempt an exposure of the estimated number of able bodied men and women that the society has lost and is in danger of losing into crime. The findings of this study will bring to the fore various ethno-cultural sentiments that inform the various ways people perceive discharged prisoners in Anambra state as well as emphasize the negative effects of cultural beliefs and practices on the reintegration needs of discharged prisoners. The government and other related organs in the society 
may by the result of this study design effective intervention programmes that will promote the smooth re-entry of discharged prisoners into the society in addition to helping to re-orientate family and societal members towards changing their views and attitude towards discharged prisoners.

Theoretically, the findings of this study will give a general idea of the number of discharged prisoners within the scope of the study areas who are in dire need of rehabilitation and re-integration and which the society is in danger of losing into crime. The study will make significant input in the body of knowledge on the socio-cultural factors that militate against the smooth reintegration of discharged prisoners in Anambra state. And finally, it will serve as a veritable source of reference for students and researchers who are interested to embark on further studies in the area of correctional studies.

\section{Efforts towards Rehabilitation and Reintegration of Discharged Prisoners}

As trend towards confining greater numbers of offenders in correctional facilities continues, increasing attention is being paid to what happens once they are released back into the community. Altshuler et al (1999) claim that "what happens" question frequently asked is in reference to two closely related issues. The first is whether released offenders will commit additional crimes, and thereby threaten public safety. The second is on the issue of what is being done to ensure that released offenders will not continue to offend. This is because there is so much uncertainty surrounding the community adjustment of offenders after release from seemingly inadequate institutional reformation and rehabilitation programmes. Some believe the best policy is prolonged incarceration. In fact, one of the motivations for prolonging incarceration, according to Altshuler et al (1999), is that confinement is regarded by some as the primary way to prevent offenders from committing additional crimes. Implicit in this view is the belief that incarceration is insufficient to prevent or deter offenders from committing crimes when released. Imprisonment has been found to be problematic for several reasons. First, it is expensive; two, there is lack of space and thirdly, it has not demonstrated measurable reduction in offender's re-arrests after release.

All over Europe and America, a number of after-care initiatives have been developed and implemented to ease the transition problems of released offenders from the prison to the communities. Such programmes as noted by Altshulae et al, (1999), Brown, Esbenson \& Geis, (2001) are; Reintegrative Confinement, Structured Transition, Intensive After-care, and Community Correction which include, Halfway Houses, Furloughs, Probation and Parole. They are briefly discussed below.

Reintegrative Confinement: This practice is under the assumption that better outcomes are apparent or that the potential to positive impact is increased when highly structured and enhanced transition from prison facilities into the community is implemented in accordance with certain specifications. These specifications include; preparing confined offenders for re-entry into the specific communities in which they will return, making the necessary arrangements and linkages with agencies and individuals in the communities that relate to known risk and protective factors and ensuring delivery of required services and supervision.

Intensive After-Care: This programme, involves progressively increased responsibility and freedom for the released offenders within the community. The programme tries to facilitate offender's community interaction and involvement in community activities including access to community support systems. The programme is designed to develop new resources, support systems and opportunities for released offenders in need. It monitors and tests the offenders at reasonable intervals. Intensive After-care community supervision to released prisoners has been found to result in their better performance and eventual resettlement within their communities.

Structured Transition: This refers to a programme that embodies other transition programmes which involve a well organized smooth reentry of a released prisoner into the community. Structured transition has to do with mental, physical and emotional preparation of the released offender to meet the challenges of the society to which he belongs. This programme is interested in better adjustment of the released prisoner within the community believing that when applied and followed conscientiously will have the potentials for transferring newly, learned skills and competencies to the very community in which they will reside

Halfway Houses: Halfway houses are another variation of community corrections, providing living quarter for inmates, while allowing unsupervised access to the community for work, school or other activities that might enhance rehabilitation and community reintegration. According to him, residential status in such facilities sometimes intercedes between prison incarceration and release from custody (halfway out).

Furloughs This is another variety of community correction programme which involves an unescorted temporary release from prison to provide the prisoner an opportunity to prepare for release from custody. It is designed to facilitate, 
work, education, family visits and other activities in order to aid reintegration.

Probation: Probation is yet another reintegration programme targeted towards offenders. It entails serving a sentence in the community under specified conditions and with supervision by a probation officer. This is developed in an attempt to reduce over-crowding and cost in the prison especially when the offence committed is minor. Typically, the conditions imposed on the probationer (offender) include requirements such as reporting to the probation officer at specified intervals, remaining within jurisdictional boundaries and refraining from consumption of alcoholic beverages etc.

Parole: Parole is the release of a convicted prisoner from prison to serve the remainder of the sentence in the community under supervision by a parole officer. This is also another community based correctional strategy that favours gradual and smooth reintegration of released offenders in their respective communities. By serving the remainder of his sentence within the community, he is monitored and helped with the community resources which will eventually aid faster readjustment and leading of a law-abiding life.

Unfortunately, in Nigeria the situation is not the same. While lip-service is paid to the existence of after-care services, provision for community based corrections is apparently not in existence. Probation and parole system which have been in practice for a very long time in most parts of Europe and America have not even been considered let alone tried, not to talk of establishing halfway houses or furloughs.

\section{References}

Altshuler, M.D., Armstrong, T.L. \& Mackernzie, D.L.(1999). Reintegration, Supervised Release and Intensive Aftercare. Juvenile Justice Bulletin: US Department of Justice.

Brooks, T. (2009). Rethinking Punishment: SSRN Rehabilittion Theory. Retrieved, 27 th February 2013 from http://www.ssrn.com labstract.

Brown, S.E, Esbonsen, F.A \& Geis, G. (2001). Criminology: Explaining Crime and its Context. Boston: McGraw-Hill Company.

Carney L.P. (1977). Probation and parole; Legal and Social Dimension. New York: McGraw Hill Book Company.

Ekpe, C.P \& Mammah, S.C (1997). Social Work in Nigeria: A colonial Heritage. Enugu: UNIK Oriental Prints Ltd.

Falobi, F. (2009). Empowering Prison Inmates. Retrieved, 21 September 2009 from http://www.independentngonline.com/

ICJIA, (2007). "Community Re-entry Challenges daunt Ex-offenders Quest for a Fresh Start". Research Brief. Vol. 2, No. 1. Retrieved 22 ${ }^{\text {nd }}$ February 2013, from: http://www.icjia.state.il.us/public/pdf/Bulletins/Community

Igbo, E.U.M (2007). Introduction to Criminology. Nsukka: Afro-Orbis Publication Ltd.

Igbo, E.U.M. \& Ugwuoke, C.U. (2003). Recidivism in Enugu State Prison. Nigeria Journal of Research and Production (NIJOREP). Vol. 3 N0. 3 Sept. 2003.

Immerwahr, J., \& Johnson, J. (2002). Prisoner Reentry and the Institutions of Civil Society: Bridges and Barriers to Successful Reintegration. Working Discussion Paper for the Urban Institute's Reentry Roundtable

Imogen, R. (2007). Roots and History of Punishment. Retrieved, 20th February 2013 from http://Voices.yahoo.com/roots-his

Match, M.W. \& Jose, B.A. (1991) Introduction to social work and social welfare. (6th ed). New York: Macmillan Publishers.

Orakwe, I. W. (2011). The Transformation Digest. A Journal of Nigerian Corrections. 1. (2). 6-12.

Osaze, L.E. (1996). Behind the Wall. Lagos: Civil Liberties Organization publishers,

Santrock, J.W. (2000). Psychology (6 $6^{\text {th }}$ ed), Boston: McGraw Hill companies

Shama, A. (2012). Ten most Brutal Methods of Ancient Civilization. Retrieved 23rd February 2013 from http;//environmentalgrsffiti.com /news-12

Ugwuoke, C. U. (2010). Criminology: Explaining Crime in the Nigerian Context. Nsukka: Great AP Publishers LTD

Umah, K. E. (2004). The Impact of Resource Allocation and Jail Term on Rehabilitation; a Ph.D Thesis Submitted to the Department of Economics University of Nigeria, Nsukka. 